\title{
COMPARISONS OF GRACE AND GLDAS DERIVED HYDROLOGICAL LOADING AND THE IMPACT ON THE GPS TIME SERIES IN EUROPE
}

\author{
Yankai BIAN ${ }^{1)}$ *, Jianping YUE ${ }^{1)}$, Zhen $\mathrm{LI}^{1)}$, Kanglin CONG ${ }^{1,2)}$, Wang LI $^{3)}$ and Yin XING ${ }^{1)}$ \\ 1) School of Earth Sciences and Engineering, Hohai University, Nanjing 211100, China \\ 2) School of Information Science and Engineering, ShanDong Agricultural University, Taian 271018. China \\ 3) School of Environmental Science and Spatial Informatics, China University of Mining and Technology, Xuzhou 221116, China \\ *Corresponding author ss e-mail: byankai@126.com
}

\begin{tabular}{l}
\hline ARTICLE INFO \\
\hline Article history: \\
Received 6 April 2020 \\
Accepted 2 July 2020 \\
Available online 20 August 2020 \\
\hline
\end{tabular}

Keywords:

GRACE

GPS

GLDAS

Hydrological load vertical deformation WTC

\begin{abstract}
The surface displacement caused by hydrological loading makes an important contribution to the non-linear crustal movement observed at the International Global Navigation Satellite System Service (IGS) stations. In this paper, the amplitude, correlation, and root mean square (RMS) of the vertical displacement time series signals of 47 IGS stations are used to analyze which data of Gravity Recovery and Climate Experiment (GRACE) or Global Land Data Assimilation System (GLDAS) can better reflect the hydrological load effect in Europe. The results show that in Europe, the hydrological load effect calculated based on GRACE data is more accurate than that of GLDAS, which has not been reported before. Then, the relationship between the GPS height and GRACE load deformation in terms of annually-oscillating signals, correlation, and phase is analyzed by using singular spectrum analysis, the Pearson correlation coefficient, and wavelet coherence (WTC). It was found that GPS and GRACE agree at some stations (e.g., BOR1 and ZIMM), while they differ significantly in amplitude and phase at other stations (e.g., KIRU and NOT1), indicating that not all GRACE-derived displacements of IGS stations can clearly explain their nonlinear motion. The correlation coefficients between GPS and GRACE are higher than 0.7 at $85 \%$ of stations. Amongst them, the values are obviously greater than 0.8 (e.g., ZIMM and LAMA) around inland areas and high mountains, and even less than 0.6 (e.g., ANKR and KIRU) along the coast of the Mediterranean ocean, which more precisely shows that the hydrological load effect has obvious spatial and regional characteristics compared with previous studies. In addition, the relative phase of the WTC solution is basically consistent under non-detrend and detrend, which shows that the relative phase difference of each station is only related to the nonlinear movement and not to the linear trend caused by the tectonic deformation. Finally, we study the influence of GRACE hydrological load on the RMS of GPS height, which is reduced by $24.60 \%$ on average, and the reduction rate distribution of the RMS is in good agreement with the spatial distribution of the correlation coefficient.
\end{abstract}

\section{INTRODUCTION}

Research and analysis of GPS coordinates time series is an important basis for studying the influence of various geophysical phenomena on the position of GPS stations, so as to further understand the real movement rules of GPS stations (Jiang et al., 2010; Jiang et al., 2014; Deng et al., 2016). Among them, there is a strong correlation between the environmental load and the nonlinear motion of GPS station coordinate time series, which is still a research hotspot (Li et al., 2018). In this case, it is necessary to consider the influence of environmental load on the GPS positioning accuracy.

The research on the environmental load caused by the nonlinear motion of GPS stations mainly includes the atmospheric, non-tidal ocean and hydrology load (see, e.g., Jiang et al., 2014). Among them, compared with the atmospheric and non-tidal ocean loads, the hydrological load is related to the continental water storage, which is defined as a virtual sum of soil moisture, groundwater, snow-pack, surface waters, and canopy water storages (e.g., Ferreira et al., 2018). The influencing factors are relatively complex and the load is not well understood (King et al., 2006; van Dam et al., 2007). In view of this study, more inland rivers and lakes in Europe and the snow in high mountain areas are deeper, which makes the signal of the water storages large enough to be sensed at the GNSS stations therein. In this regard, the hydrological load effect is different from other previous study areas. In addition, the GPS stations are relatively dense, stable, and the coordinated data quality is good, so it is worth exploring. Therefore, the above mentioned factors urge us to use different geodetic techniques to study the regional crustal deformation in Europe caused by the hydrological load. 
At present, some scholars use different hydrological models to study the influence of the hydrological load on the nonlinear motion of GPS stations by the Green function (van Dam et al., 2001; Rajner et al., 2011; Jiang et al., 2013; Dill et al., 2013; Dill et al., 2015; Xu et al., 2017a; Li et al., 2017a; Knappe et al., 2019). In addition, with the Gravity Recovery and Climate Experiment (GRACE) satellite, some scholars have begun to use GRACE to monitor the hydrological load deformations, albeit spectral inconsistencies have been reported between the two products (Ferreira et al. 2020). They are used to modify the periodic signals in the GPS time series, reduce the impact of the seasonal load deformation on them, and so improve the GPS positioning accuracy (Lavallée and Blewitt, 2002; Van Dam et al., 2007; Tregoning et al., 2009; Fu and Freymueller, 2012a; Fu and Freymueller, 2012b; Hao et al., 2016; Han et al., 2005; Ding et al., 2018; Li et al., 2019). At the same time, some scholars have combined GPS, GRACE and the hydrological model to study the load effect of the surface quality. Davis et al. (2004) pointed out that the results observed by GPS were more consistent than those detected by GRACE in monitoring the vertical deformation of the hydrological load, which was significantly larger than that of the hydrological model. Van Dam et al. (2011) quantified mass loading model errors by comparison to global GPS position time series, and the results showed that the reprocessed GPS vertical coordinates can be used to estimate the reliability and accuracy of the environmental data sets. Nahmani et al. (2012) found that the comparison between GPS and Surface Loading Models (SLMs) in vertical deformation was better than that of GPS and GRACE for stations outside the African monsoon region, which indicated that GRACE cannot detect local loading deformations, but GPS and SLMs can. Jiang et al. (2013) used three different environmental load methods to estimate and nonlinearly modify the surface displacement in a set of GPS high time series and found that there were differences in the reduction of site scattering. Moreira et al. (2016) showed that the deviation between the monthly vertical component of GPS and GRACE was smaller than that of the global hydrological model among the 18 GPS stations of the Amazon basin, although the root mean squares (RMS) variation of the GPS series accounts for up to $70 \%$. $\mathrm{Wu}$ et al. (2017) found that the seasonal crustal vertical deformation measured by GPS was more consistent with the results obtained by SLMs than GRACE, in the Tianshan area, and the correlation was better, mainly due to the influence of the atmospheric load. For the European region, some scholars have not combined GPS, GRACE and the hydrological model, and the load data sources used are different (e.g., Van Dam et al., 2007; Ma, 2017). Xiang et al. (2019) used GPS, LSDM and GRACE data to study the seasonal crustal deformation in the Asian continent, and found that the hydrological load effect of LSDM is better than that of GRACE, and can effectively improve GPS observations. Although some previous studies have been carried out, there are obvious differences in hydrological load effects in different regions, and the selection of hydrological models will be different. Especially for the processing of GRACE data by previous scholars, RL05 data is mainly used before single filtering processing. In this study, RL06 data and the combined filtering method are used, so the GRACE data accuracy will be higher. In addition, in the hydrological load and GPS phase analysis, the influence of data non-detrend was not considered. Europe is rich in water resources, which makes it different from the other research areas. Therefore, on the basis of previous works, this paper attempts to use the data sets of GPS, GRACE and GLDAS to characterize the hydrological load effect in Europe, and to determine which data in GRACE and GLDAS is better for hydrological load effect. In addition, the influence of the data on the relative phase calculation of WTC under non-detrend is studied. Meanwhile, we also discuss the influence of the hydrological load on GPS observation from the change of RMS value, which helps us to better understand the seasonal oscillation in GPS observation from the perspective of the hydrological load.

In this paper, the least square fitting (LSF) method is used to extract the seasonal signal of GPS height and vertical deformation of the hydrological load of GRACE and GLDAS (e.g., Ferreira et al. 2019). The differences between them are compared and analyzed from multiple perspectives (e.g., Amplitude, Correlation, RMS) to verify which of GRACE or GLDAS can better reflect the European regional hydrological load effect. Then, the relationship between the vertical deformation of the GRACE hydrological load and GPS height time series is studied by using the method of SSA, Pearson seasonal correlation analysis, and wavelet coherence (WTC) relative phase analysis. Among them, when calculating the relative phase of WTC, the influence of detrend and non-detrend processing of GPS and GRACE data is discussed, and whether the phase difference is only related to the GPS nonlinear motion, is analyzed. Finally, the correction effect of the GRACE hydrological load on GPS height is quantitatively analyzed by reducing the RMS of the GPS height, which is used to explain the partial nonlinear motion of GPS stations caused by hydrological load.

\section{DATA AND METHODS \\ 2.1. GPS DATA}

The daily GPS time series data that we use comes from the International Global Navigation Satellite System Service (IGS), which is a series of coordinated data combined solutions and can be found at (http://garner.ucsd.edu/pub/time series) (Dow et al., 2009; Rodriguez-Solano et al., 2014). The GPS observation data are processed tightly with GAMIT and GIPSY software, and the one-day relaxation constraint solution is obtained. Then, the exact positions of GPS stations relative to the coordinate 


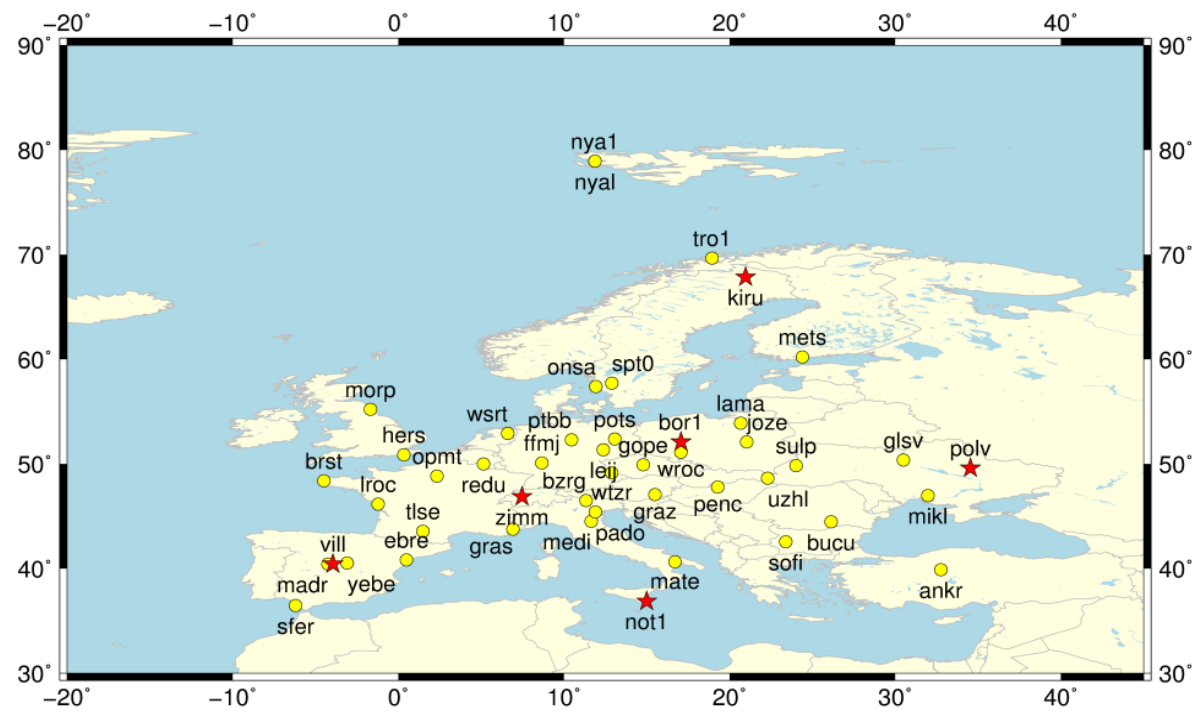

Fig. 1 Spatial position distribution map of GPS stations over Europe: the red pentagons represent the experimental analysis stations (BOR1, KIRU, NOT1, POLV, VILL and ZIMM), and the yellow dots represent the remaining 41 stations.

reference frame ITRF 2014 are obtained. In theory, the accuracy of the daily GPS position time series should be at the millimeter-level in the horizontal components, and at the centimeter-level in the vertical components.

The combined solution is an advantage of accepting different analysis center solutions and reducing the random noise generated in a single analysis process, which improves the signal-to-noise ratio (van Dam et al., 2007). Fritsche et al. (2012) confirmed that the scattering of the vertical component of the combined solution weight was $5-15 \mathrm{~mm}$ smaller than that of any single analysis. We removed outliers, offsets, and linear trends, as in Nikolaidis et al. (2002). At the same time, considering the problem of missing data, and based on the basic principle: the number of consecutive data intervals at each station shall not exceed 15 , and the ratio of missing data to the whole observation values shall not exceed $1 \%$ (e.g., Li et al., 2017b). In the analysis, the SSA iteration is adopted to carry out the data gap-filling with the aid of Singular Spectrum Analysis-MultiTaper Method (SSA-MTM) Toolkit (Vautard et al., 1992).

According to the above GPS data processing strategy, the effects of atmospheric, non-tidal-ocean and hydrological load are still retained in the GPS vertical coordinate time series (Geng et al., 2012). In this study, in order to maintain the consistency of GPS observation data with the GRACE and GLDAS hydrological load deformations, we removed the atmospheric and non-tidal-ocean load data provided by the Global Geophysical Fluid Center (GGFC), from the vertical coordinate time series of the daily GPS station (http://loading.u-strasbg.fr/itrf/cf/). In addition, we have taken the mean over the 30-days period of GPS. Considering that the European plate is a tectonic stable area with minimal tectonic noise, we selected 47 GPS stations located on the European plate from January 2003 to December 2016, for analysis (Fig. 1).

\subsection{GRACE DATA}

The GRACE satellite tracks the ranging rate and distance between two satellites by the K-band ranging (KBR) system to observe the change in the Earth's gravity (Cazenave et al., 2010). Since April 2002, the global and regional land water mass redistribution has been constrained by the monthly GRACE gravity changes and monitored at a spatial resolution of about $330 \mathrm{~km}$ (Wahr et al., 1998). Compared with the Center for Space Research (CSR) Level 2 RL05 data, the RL06 data (http://icgem.gfz-potsdam.de/grace/level2/csr/r106) has some advantages in periodic change, accuracy, and spatial resolution characteristics (Göttl et al., 2018; Bian et al., 2019). Therefore, the data of CSR RL06 is used in this study.

Vertical crustal deformation of the Earth's surface caused by land water migration can be obtained by a set of load Love and spherical harmonic coefficients (SHCs) of the gravity field, as follows (e.g., Kusche et al., 2007; van Dam et al., 2007):

$$
\begin{aligned}
\Delta r(\theta, \lambda) & =R \sum_{l=1}^{N_{\max }} \sum_{m=1}^{l} \frac{h_{l}^{\prime}}{1+k_{l}^{\prime}}\left(\Delta C_{l m} \cdot \cos (m \lambda)+\right. \\
& \left.+\Delta S_{l m} \cdot \sin (m \lambda)\right) \tilde{P}_{l m}(\sin (\theta))
\end{aligned}
$$

where $\Delta r(\theta, \lambda)$ is the vertical displacements of the Earth's surface, $R$ is the average radius of the Earth $(6371 \mathrm{~km}), \lambda$ and $\theta$ are the longitude and latitude, $\Delta C_{l m}$ and $\Delta S_{l m}$ are the coefficients changes of the normalized complex spherical harmonic (Stokes' coefficients), $\tilde{P}_{l m}(\sin (\theta))$ is the fully normalized Legendre function of degree $l$ and order $\mathrm{m}, N_{\max }$ is the maximum coefficient of the gravity field model 60 , and $h_{l}^{\prime}$ and $k_{l}^{\prime}$ are the load Love numbers of order $l$ provided by Farrell (1972). 
The data has been processed in a series of ways, mainly in that the Degree 2 coefficients obtained by Satellite Laser Ranging (SLR) are used to replace the C20 terms with high uncertainty (Chen et al., 2005), the geocentric correction terms (S11, C11 and C10) are estimated by Swenson et al. (2008), and the Glacial Isostatic Adjustment (GIA) is corrected based on the model provided by Geruo et al. (2013). In addition, in order to eliminate the North-South "strip" error and high-frequency error caused by the inversion process, the combination filtering form of Gaussian filter and P4M6 de-correlation filter is adopted (Swenson et al., 2006; Han et al., 2010; Chen et al., 2009).

The time span is 154 months from January 2003 to December 2016, which is the same period as for the GPS stations. The missing data are filled with the cubic spline interpolation method, and 168 month's data are obtained.

\subsection{HYDROLOGICAL LOADING DEFORMATION}

The surface load models are used for comparison with GRACE and GPS data, which include terrestrial water storage loading. Among them, the terrestrial water storage is the main source of mass variation at a seasonal timescale (Velicogna et al., 2001; Nahmani et al., 2012). For the mass loads we use products from the GGFC available from the School and Observatory of Earth Sciences (EOST) load service. Among them, the hydrological load (soil moisture, canopy water and snow) comes from the data released by the GLDAS/Noah v1.0 (Rodell et al., 2004), with a spatial-temporal resolution of 3 hours and 0.25 degrees, respectively, and the areas covered by permanent ice and snow (Greenland, Alaska and Alpine glaciers) are removed (Rui, 2011). The product data is obtained from http://loading.u-strasbg.fr/itrf/cf/, in order to compare with GPS and GRACE data.

\subsection{WAVELET COHERENCE METHOD}

Firstly, we briefly describe the continuous wavelet transform (CWT) before introducing the WTC method. The CWT definition of time series $\left(X_{n}, \mathrm{n}=1,2, \cdots, \mathrm{N}\right)$ is defined as (Grinsted et al., 2004):

$$
W_{n}^{X}(s)=\sqrt{\delta t / s} \sum_{n^{\prime}=1}^{N} X_{n^{\prime}} \varphi_{0}\left[\left(n^{\prime}-n\right) \frac{\delta t}{s}\right]
$$

where $W_{n}^{X}(s)$ is the wavelet coefficient, $\mathrm{s}$ is the wavelet scale, $\varphi_{0}$ and $\delta t$ are the mother wavelet function and the time scale, respectively, and $\sqrt{\delta t / s}$ and $n^{\prime}$ represent the normalization factor and the reversed time, respectively. The idea of wavelet transform is that the wavelet as a band-pass filter is applied to time series where the characteristic period of the filter is linearly related to the wavelet scale. Based on the CWT, the WTC of two time series $X_{n}$ and $Y_{n}(\mathrm{n}=1,2, \ldots, \mathrm{N})$ is defined as (Grinsted et al., 2004):

$$
R_{\mathrm{n}}^{2}(s)=\frac{\left|S\left(s^{-1} W_{\mathrm{n}}^{X Y}(S)\right)\right|^{2}}{S\left(\mathrm{~s}^{-1}\left|W_{n}^{X}(s)\right|_{2}\right) \cdot S\left(\mathrm{~s}^{-1}\left|W_{n}^{Y}(s)\right|_{2}\right)}
$$

where $S$ is the smoothing operator, $W_{n}^{X}(s)$ and $W_{n}^{Y}(s)$ are the wavelet coefficients of $X_{n}$ and $Y_{n}$ time series, $W_{\mathrm{n}}^{X Y}(S)$ is their cross-wavelet transform, the complex $\operatorname{argument} \arg \left(W_{\mathrm{n}}^{X Y}(S)\right)$ is the local relative phase between $X_{n}$ and $Y_{n}$ in time-frequency analysis, $R_{n}(S)$ is the local correlation coefficient, $s$ is the wavelet scale, and $n$ is the number of stations. The advantage of WTC is that it can reveal the significant correlation regions of two time series in time-frequency domain, and further reveal their relative phases in the region. In analysis, we use the circular mean of the phase and WTC-based semblance to quantify the phase relationship and correlation between two time series. The circular mean of a set of angles $\left(\alpha_{i} \mathrm{i}=1,2, \cdots, \mathrm{N}\right)$ is defined as:

$$
a_{m}=a \tan 2(X, Y)=a \tan 2\left(\frac{1}{n} \sum_{i=1}^{n} \cos \left(\alpha_{i}\right), \frac{1}{n} \sum_{i=1}^{n} \sin \left(\alpha_{i}\right)\right)
$$

We can use circular standard deviation $s=\sqrt{-2 \ln (R / n)} \quad\left(R=\sqrt{X^{2}+Y^{2}}\right)$ to qualify the scatter of angles around the mean. The WTC-based semblance is defined as (Cooper et al., 2008):

$\rho=\cos \left(\alpha_{i}\right)$

The range of the $\rho$ value is - 1 to 0 to 1 , which is expressed as negative correlation, irrelevant correlation and positive correlation, respectively. Among them, the closer the value of $\rho$ is to 1 , the greater the correlation. In this analysis, we compare the two time series by using WTC-based semblance.

\section{RESULTS}

Based on the above data processing strategy, the time series of vertical deformation of GPS, GRACE and GLDAS for 47 IGS stations were obtained. For this time series, we removed the linear trend caused by the tectonic changes (Tregoning et al., 2009; Fu et al., 2012b; Liu et al., 2017). Thus, a more suitable hydrological load deformation monitoring model can be selected from GRACE and GLDAS to modify the vertical coordinate time series of GPS stations. In order to further analyze the correlation among the three time series, the mean, annual and semi-annual, and trend signals (Nikolaidis, 2002) are calculated by equation (6).

$$
\begin{aligned}
y & =a+b t+c \sin (2 \pi t)+d \cos (2 \pi t)+ \\
& +e \sin (4 \pi t)+f \cos (4 \pi t)
\end{aligned}
$$

where $t$ is the time resolution period, $a$ is a constant, $b$ is linear transformation rates, and $c, d, e$, and $f$ are annual and semi-annual periodic motions, respectively. 

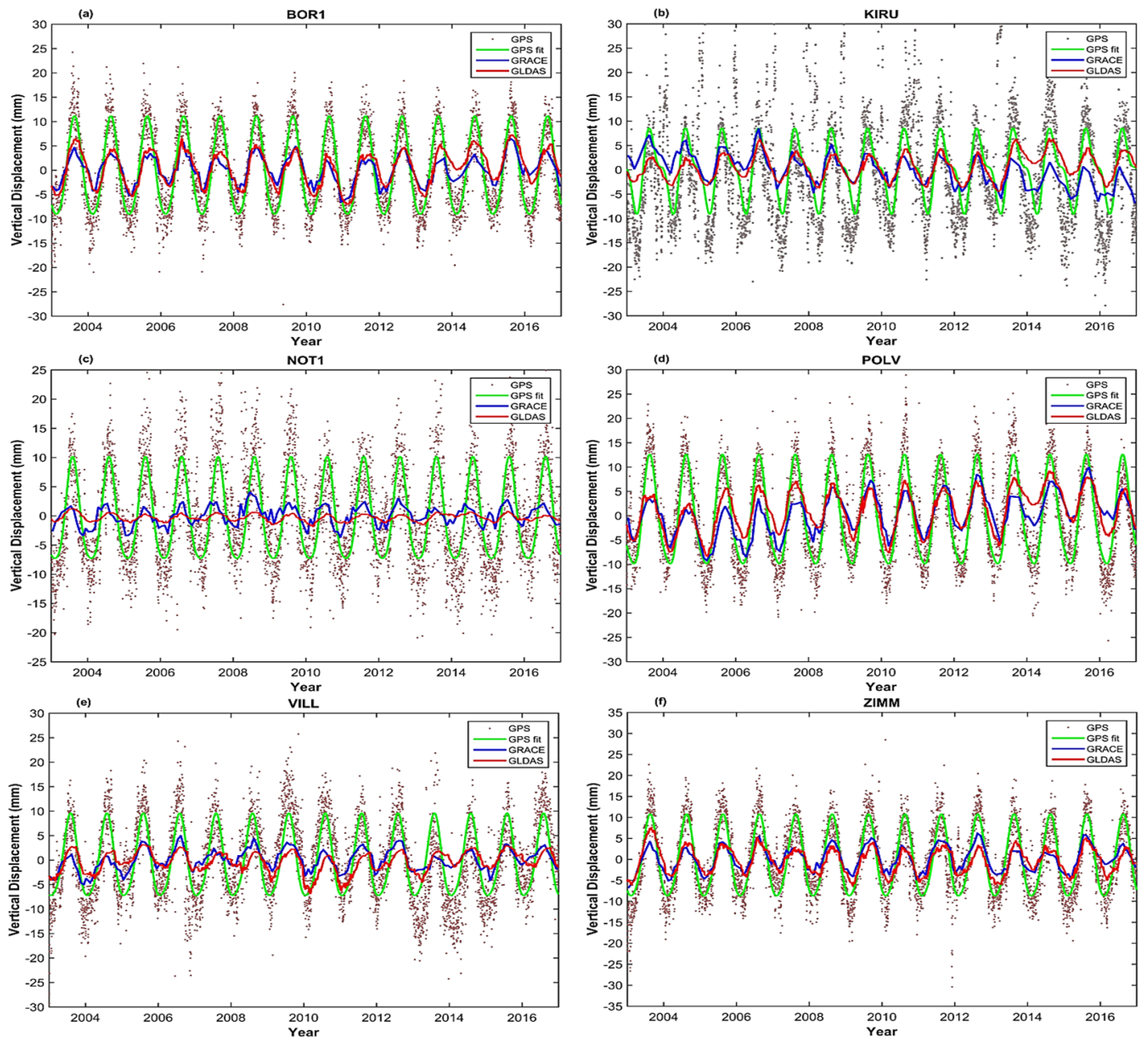

Fig. 2 Detrend vertical deformations time series of GPS, GRACE and GLDAS data for the 6 GPS experimental stations. The grey dots, green lines, blue lines and red lines represent the time series of GPS, GPS fitting, GRACE and GLDAS, respectively.

\subsection{SEASONAL VERTICAL CHANGE ANALYSIS IN GPS, GRACE AND GLDAS}

Figure 2 shows the vertical deformation of the 6 GPS experimental stations detrend time series in the study area. As can be seen from the graph, the vertical deformations acquired by GPS, GRACE and GLDAS all show obvious seasonal signals. For the BOR1, POLV, VILL and ZIMM stations, the vertical deformation derived from GRACE and GLDAS has a good consistency, and the amplitude is smaller than the GPS in amplitude, indicating that they may be only part of the reason for the non-linear vertical motion of the GPS stations. However, at the NOT1 and KIRU stations, the vertical deformation signals from GPS, GRACE and GLDAS are different, so it cannot be determined which of GRACE and GLDAS is the better. This conclusion is not completely consistent with other scholars (van Dam et al., 2007; Ma, 2017), but is an improvement on previous studies. Then, we analyzed the time series mean values of all the stations deformation. As can be seen in Figure 3, the phase is basically the same, and the amplitude floating is that the deformation derived from the GRACE data is relatively larger than that from the GLDAS data, and both are smaller than that from GPS. In a word, it shows that the GRACE monitoring hydrological load effect is better than that of GLDAS in Europe, which is basically consistent with the analysis of Ferreira et al. (2019) regarding South America.

Here, in order to further determine which observation method of hydrological vertical deformation derived from GRACE/GLDAS is better, we provide detailed statistical results from the aspects of correlation and RMS. In terms of correlation, from Figure 4, we can see that most of the stations show a strong correlation between GPS and GRACE/GLDAS. In these stations, the correlation coefficient between GPS and GLDAS is more than 0.7 for $66 \%$ of the stations, for GPS and GRACE, $79 \%$ of the stations have a correlation coefficient of more than 0.7, indicating that seasonal variations may originate from the same geophysical processes, but GRACE performs better. Finally, we can see from Figure 5 that the RMS value of the GPS high time series changes from $7.26 \mathrm{~mm}$ to $11.83 \mathrm{~mm}$, which is larger than for GRACE and GLDAS. At the same time, the RMS value of GRACE is very close to that of GLDAS, but the RMS value of GRACE is less than 


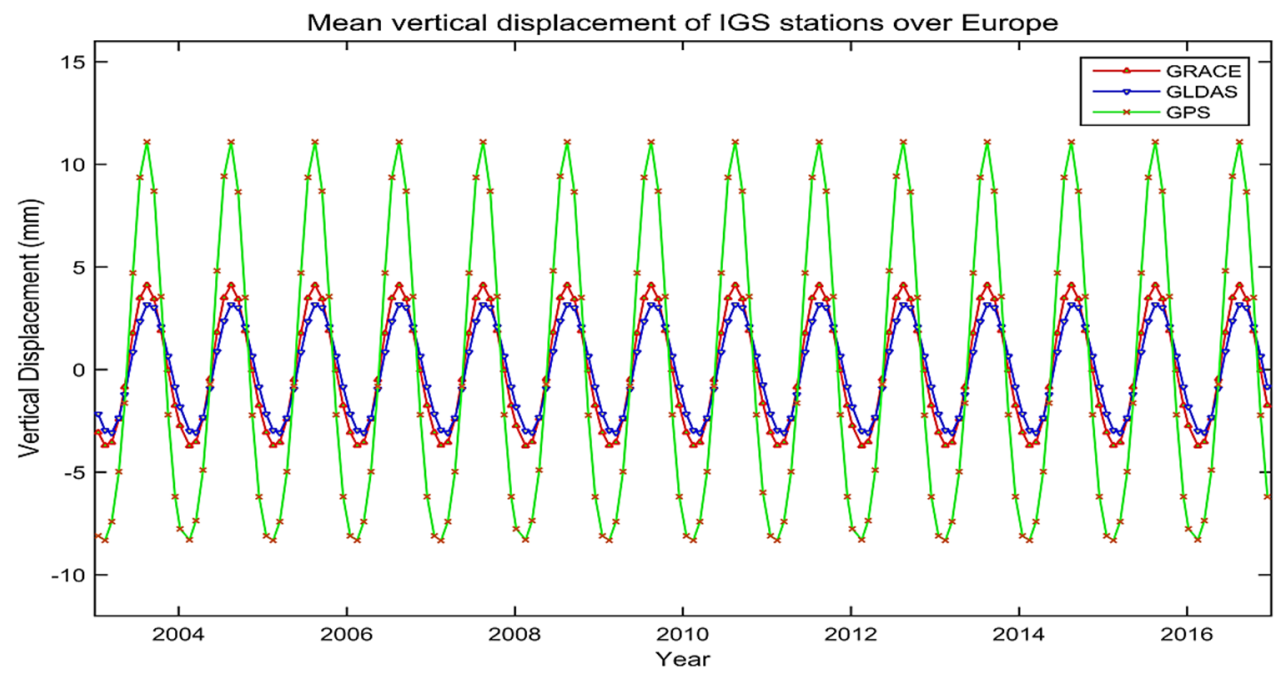

Fig. 3 Mean vertical displacement of IGS stations over European from GRACE, GLDAS and GPS data. The red, blue and green lines represent the time series of GRACE, GLDAS and GPS data, respectively.

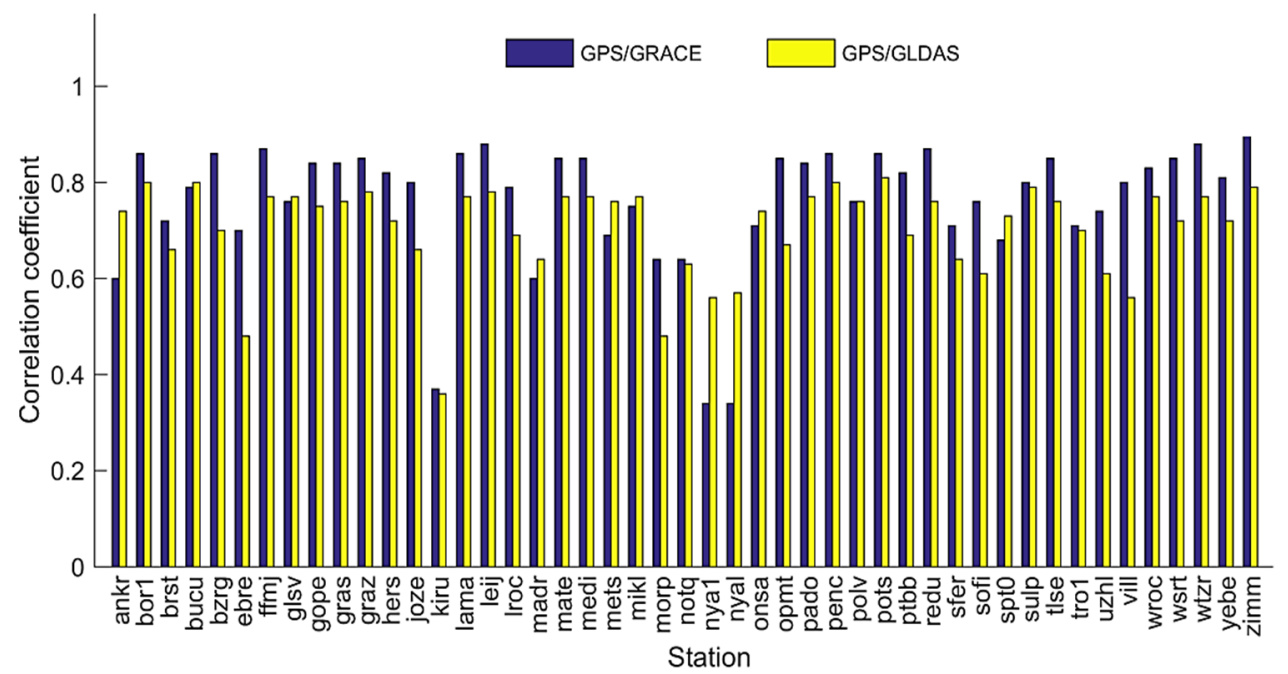

Fig. 4 The correlation coefficient between GPS height and vertical deformation of GRACE and GLDAS at all stations.

that of GLDAS in general, which indicates that the amplitude and scatter of the GRACE hydrological load seasonal fluctuation signal is better than that of GLDAS. In conclusion, in Europe, the vertical deformation derived from GRACE can better reflect the hydrological load deformation of GPS stations than that from GLDAS.

\subsection{COMPARISON AND ANALYSIS OF VERTICAL DEFORMATION IN GPS AND GRACE}

\subsubsection{ANNUAL PERIOD SIGNAL AND CORRELATION ANALYSIS}

According to the comparative study of GPS, GRACE and GLDAS on the vertical deformation of the hydrological load, their seasonal variations are mainly reflected in annual periodic variations, and GRACE is better than GLDAS in Europe. Then, in order to study the contribution and influence of the GRACE hydrological load on the nonlinear motion of GPS, the atmospheric and non-tidal ocean loads are not processed.
To compare the difference of annual periodic oscillation signal more accurately between the GPS height and the GRACE hydrological load vertical deformation, we use the method of SSA to extract the signal respectively, which is better than the method of LSF and Kalman filtering (Li et al., 2017b; Klos et al., 2018). However, for more details on SSA, refer to the work of Ghil et al. (2002). According to the time series analysis of each station in the previous section, we selected two typical stations for annual periodic oscillation analysis. Figure 6 shows the changes of GPS height time series and vertical deformation of the GRACE hydrological load in the annual periodic oscillation signal of the two stations. In addition, it can also be clearly found that although the vertical deformation amplitude derived from GRACE at the ZIMM station is smaller than that derived from GPS, the coincidence between them is relatively high, which indicates that the GRACE-derived displacement can well explain the nonlinear motion of the GPS station at the ZIMM station. However, for the KIRU station, 


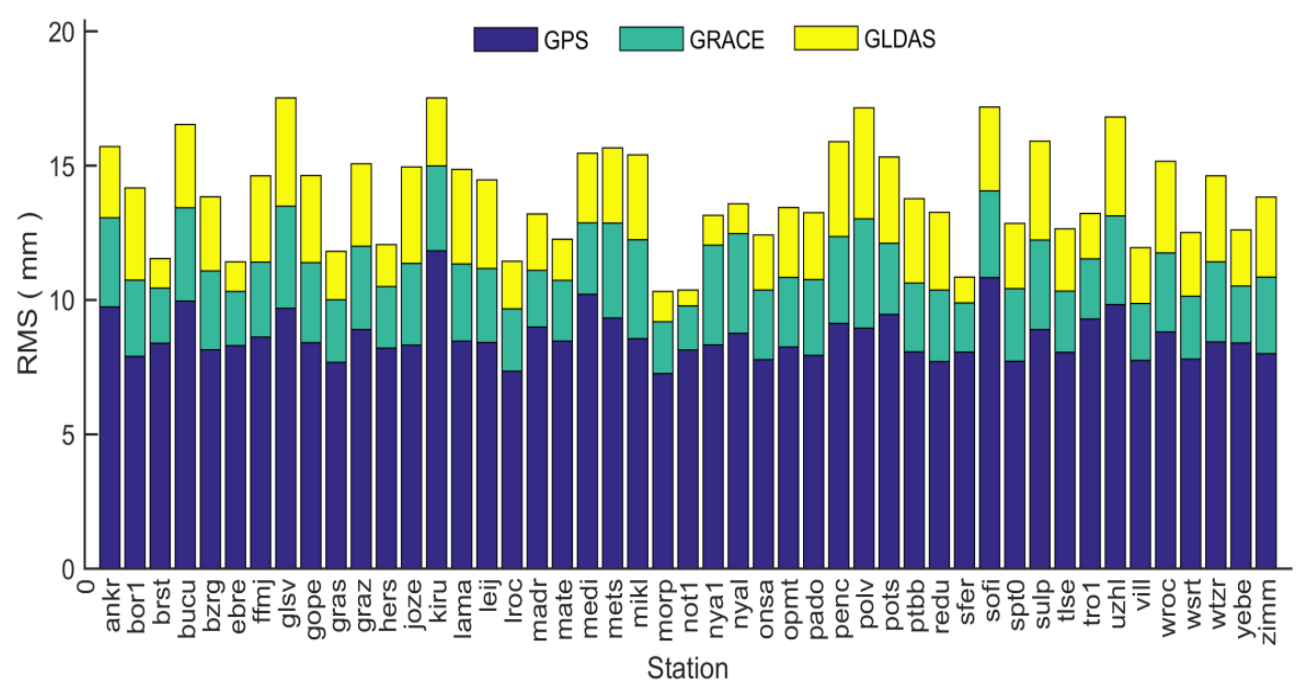

Fig. 5 RMS values of GPS height, GRACE and GLDAS vertical deformation at all stations.
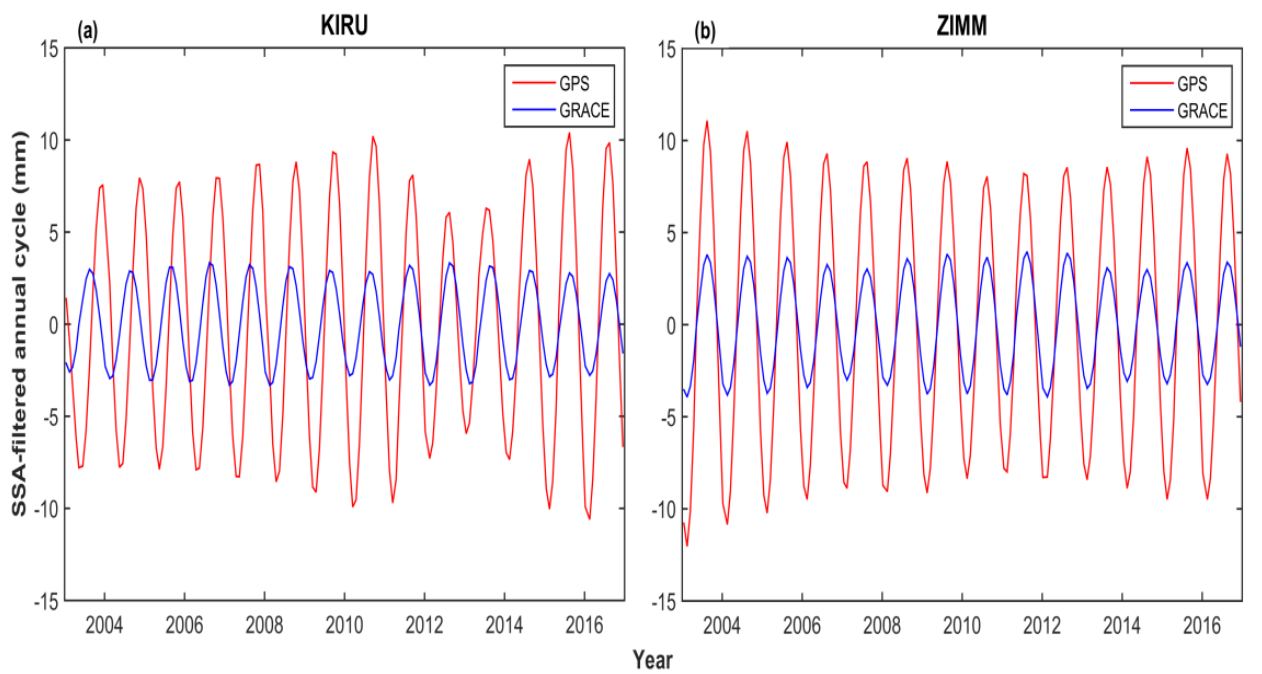

Fig. 6 (a) Annual periodic oscillation signals of station KIRU on GPS height and GRACE hydrological load deformation; (b) Annual periodic oscillation signals of station ZIMM on GPS height and GRACE hydrological load deformation.

there is a great difference between them, and the phase is not synchronized.

Pearson correlation analysis was applied to investigate the correlation between GPS height and the vertical deformation of the GRACE hydrological load. Figure 7 shows that GPS height and GRACE hydrological load deformation are positively correlated for all GPS stations in the study area, and most of them are strongly correlated (correlation coefficient is greater than 0.7 ). Among them, $85 \%$ of the stations have a correlation coefficient of more than 0.7 and an average correlation coefficient of 0.77 , which indicates that their geophysical processes may be the same and have a significant hydrological load effect. At the same time, it can be found that the correlation coefficients of stations in inland areas and around high mountains are significantly greater than 0.8 (e.g., ZIMM and LAMA), while the correlation coefficients of stations in the Mediterranean and the coastal ocean are relatively small, even less than 0.6 (e.g., ANKR and KIRU). It indicates that the vertical effect of the hydrological load has obvious spatial and regional characteristics for GPS stations in Europe.

\subsubsection{WAVELET COHERENCE ANALYSIS}

Considering that Pearson correlation analysis is only a type of correlation in the time domain, there are still several problems in analyzing the special relationship between the GPS height and the GRACE hydrological load vertical deformation. On the one hand, the seasonal signals between them are mainly reflected in the annual period or other parts, as well as in frequency. In addition, the correlation and phase relationship between them may change over time. Therefore, we propose to use the WTC method to solve the above problems. For the GPS and GRACE data, the relative phase is calculated by non-detrend and detrend, respectively, to analyze the influence of tectonic deformation on them, which is different from previous studies ( $\mathrm{Li}$ et al., 2017a, 2018; Wu et al., 2017). 


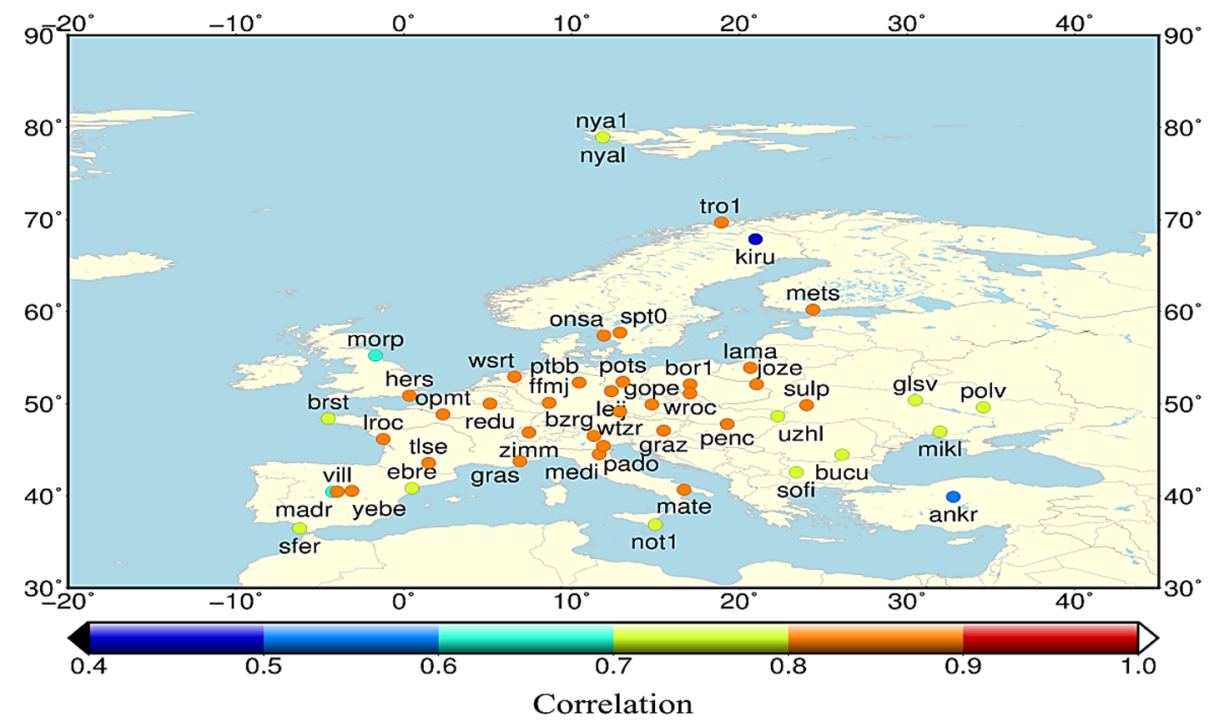

Fig. 7 Correlation between vertical deformation time series of non-linear hydrological load derived from GPS and GRACE data in the 47 stations.

Figure 8 shows the WTC spectra of GPS height and GRACE-derived vertical deformation time series at the KIRU and ZIMM stations. The reason why we chose these two sites is that in Figures 2 and 6, they have the maximum opposite correlation and phase, which are the most representative. The thick contour represents a $95 \%$ confidence interval for the red noise, and the phase of the area that is outside the cone of influence (CIO) is not included because of the edge effect. This relative phase relationship is represented by arrows. For example, the reverse phase points to the left, the same phase points to the right, and the vertical deformation of the GPS high lag behind the GRACE hydrological load, points in the vertical direction (Chen et al., 2011). Notably, the assumed noise model used in wavelet coherent code, as developed by Torrence and Compo (1998) and Grinsted et al. (2004), is a first-order autoregressive (AR (1)) process. However, many studies have confirmed that the noise model in the GPS time series is mainly a power-law (PL). In this regard, this may lead to unreliable conclusions. Considering the influence of the hypothesized noise model, the method proposed by $\mathrm{Xu}$ (2017b), which extends the significance test with the Generalized Gauss Markov (GGM) stochastic model as the null hypothesis, is used to solve this issue. Langbein (2004) proposed a GGM stochastic model, in which AR (1) and PL are special cases. The spectral form of GGM is as follows (Bos et al., 2014):

$P(f)=\frac{2 \sigma^{2}}{f_{S}^{2}\left[1+\alpha^{2}-2 \alpha \cos \left(2 \pi f / f_{s}\right)\right]^{d}}$

where $f_{s}$ is the sampling frequency. For special cases when $\alpha=1$, GGM is equal to standard PL, and when $\mathrm{d}=1$, GGM converts into AR (1). Among them, the noise model GGM + WH is utilized to establish a null hypothesis for the significance test.

Figure 8 shows that the correlation between the two time series is quite high at the frequency closest to one cycle per year (cpy). From Figures $8 \mathrm{a}$ and $8 \mathrm{~b}$, we can see that there are some differences in the relative phase of the KIRU stations under non-detrend and detrend, and some significant local correlations are also different in the spectrum and period, but the overall difference is small, indicating that we do not consider detrending for the station. In addition, it can be seen that the time series relative phase of GPS observation and GRACE hydrological load vertical deformation are not in-phase at the period nearest to one-year for the KIRU station. This indicates that the hydrological load deformation does not represent the driving factor of the GPS observation annual fluctuation. Meanwhile, for the high frequency part (period less than 8 months), although some significant local correlations are detected, their relative phase angle fluctuates sharply indicating that their phase is not synchronous. Therefore, the evidence supports that the hydrological load effect cannot explain the subseasonal oscillation in GPS observations (Ray et al., 2013; Li et al., 2018). In Figures 8c and 8d, it can be seen that the relative phase of the ZIMM station is basically consistent with that of non-detrend and detrend, indicating that the relative phase of the WTC solution can be solved without detrend processing. Meanwhile, it can also be seen that the time series of GPS observation and GRACE hydrological load vertical deformation are in phase at the closest period of 1 year for the ZIMM station, and the correlation coefficient is between 0.9 and 1 . This indicates that the hydrological load of the ZIMM station contributes to the low frequency components of the GPS observation, which is the main reason for the annual fluctuation of the GPS high time series.

From Table 1, we can see that the average relative phase angle of all stations in the high power resonance period of nearly one year ranges from $-31^{\circ}$ to $33^{\circ}$, and the overall performance is relatively stable. At the same time, the relative phase angle is basically 
(a) Non-detrend KIRU

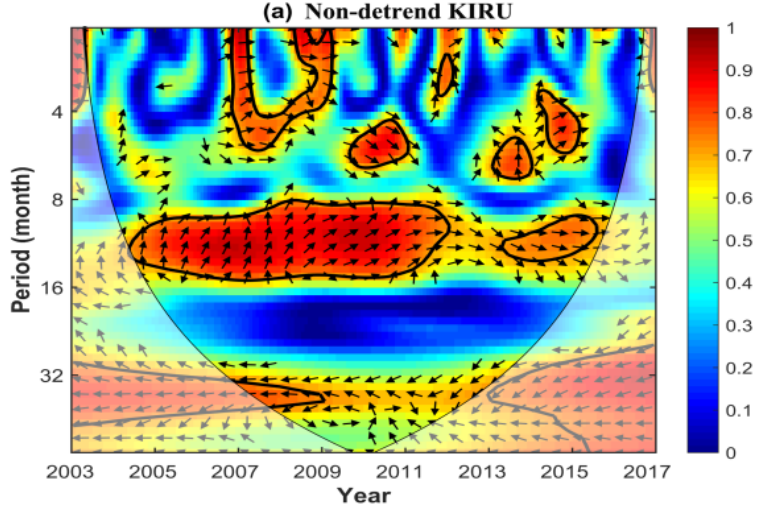

(c) Non-detrend ZIMM

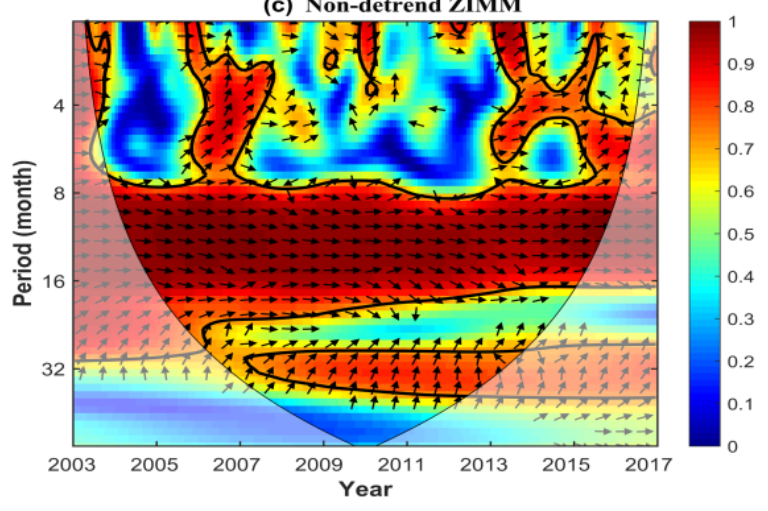

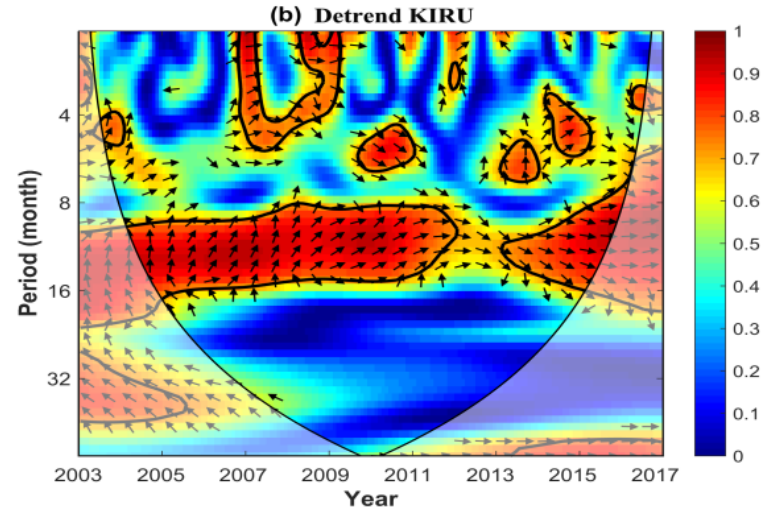

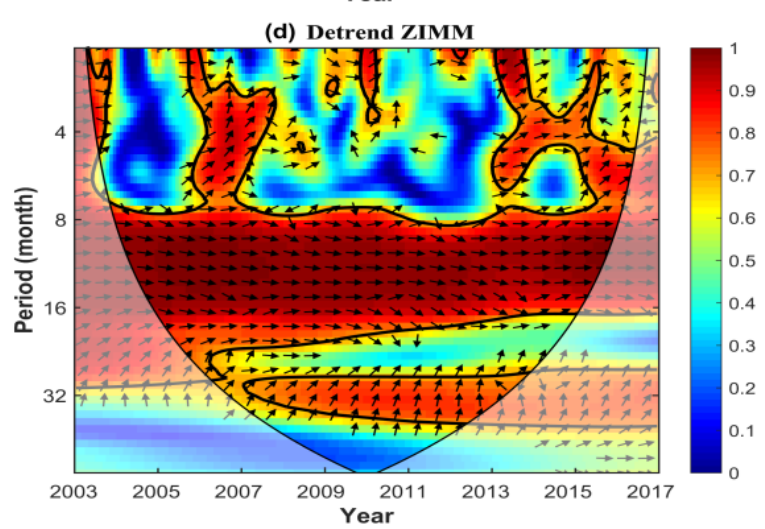

Fig. 8 Station KIRU (a) non-detrend and (b) detrend, station ZIMM (c) non-detrend and (d) detrend, the WTC spectra in GPS height and GRACE- derived vertical deformation time series.

consistent under the data of non-detrend and detrend, and the maximum difference is about $1^{\circ}$ for the KIRU station, which has little influence. In this regard, we find that the relative phase difference between GPS and GRACE stations is only related to the nonlinear movement and not to the linear trend caused by longterm tectonic deformation.

Since, in the range of annual fluctuation, the relative phase angle of the time variable is very small, the average WTC-based semblance is calculated to quantitatively express the relative phase between the two signals. The same method is used to deal with other stations in the study area. As shown in Figure 9, the average WTC-based semblance for most (but not all) stations is close to 1 , which indicates that the vertical deformation of the GRACE hydrological load is not the complete expression of the driving force for the non-linear motion of the GPS stations. At the same time, we can also see that the average WTC-based semblances of the ANKR, KIRU, and MIKL stations are not more than 0.86 , while the other stations are close to 0.96-1.0, indicating that the phase synchronization of most stations is only asynchronous in some stations. However, the correlation between Figures 7 and 9 is different, mainly because Figure 9 shows the correlation of the annual periodic signals, while Figure 7 shows the correlation of the nonlinear periodic signals. This shows that the correlation of the annual periodic signals is relatively higher than that of the nonlinear periodic signals. In addition, we can also see that the average phase semblance of non- detrending stations is basically consistent with detrending, so WTC can solve the relative phase without detrending.

\subsubsection{QUANTITATIVE ASSESSMENT THE IMPACT OF HYDROLOGICAL LOAD ON GPS HEIGHT}

The reduction of RMS is a common statistical approach used for quantitative comparison of the observed and model deformation, as well as for evaluation of the hydrological load on the GPS high time series (Dixon, 1991; Tregoning et al., 2009; Fu et al., 2012b). The RMS reduction rate expressed as a percentage (RMS \%) is used to quantify the correction performance of the GRACE hydrological load model for GPS station coordinates. It is defined as:

$$
\Delta R M S \%=\frac{R M S(G P S)-R M S(G P S-G R A C E)}{R M S(G P S)}
$$

Figure 10 shows the percentage reduction of RMS in the GPS high time series. It can be seen that the percentage reduction of RMS has obvious spatial and regional characteristics in the revised GPS height. In the study area, the percentage of RMS reduction of the inland stations is generally large, especially around the high mountains, such as the ZIMM station around the Alpine Mountains, and the REDU, WTZR and JOZE stations in the Inland areas. However, for the Mediterranean and coastal sites, such as the ANKR, KIRU and NOT1 stations, the RMS reduction is 
Table 1 The average relative phase angles between GPS and GRACE time series of hydrological load vertical deformation from the 47 stations.

\begin{tabular}{|c|c|c|c|c|c|}
\hline Station & Non-detrend & Detrend & Station & Non-detrend & Detrend \\
\hline ankr & $31.5^{\circ}$ & $31.4^{\circ}$ & nyal & $-7.1^{\circ}$ & $-6.5^{\circ}$ \\
\hline bor1 & $10.6^{\circ}$ & $10.5^{\circ}$ & nyal & $-6.1^{\circ}$ & $-6.1^{\circ}$ \\
\hline brst & $-13.1^{\circ}$ & $-13.3^{\circ}$ & onsa & $-1.4^{\circ}$ & $-0.8^{\circ}$ \\
\hline bucu & $30.6^{\circ}$ & $30.9^{\circ}$ & opmt & $-1.9^{\circ}$ & $-1.9^{\circ}$ \\
\hline bzrg & $8.8^{\circ}$ & $8.9^{\circ}$ & pado & $14.8^{\circ}$ & $14.7^{\circ}$ \\
\hline ebre & $-7.5^{\circ}$ & $-7.9^{\circ}$ & penc & $23.8^{\circ}$ & $23.6^{\circ}$ \\
\hline ffmj & $8.7^{\circ}$ & $8.5^{\circ}$ & polv & $30.0^{\circ}$ & $30.0^{\circ}$ \\
\hline glsv & $30.0^{\circ}$ & $30.0^{\circ}$ & pots & $8.2^{\circ}$ & $8.3^{\circ}$ \\
\hline gope & $21.8^{\circ}$ & $21.8^{\circ}$ & ptbb & $2.5^{\circ}$ & $2.6^{\circ}$ \\
\hline gras & $-2.2^{\circ}$ & $-2.2^{\circ}$ & redu & $1.4^{\circ}$ & $1.5^{\circ}$ \\
\hline graz & $18.8^{\circ}$ & $18.9^{\circ}$ & sfer & $-28.2^{\circ}$ & $-28.1^{\circ}$ \\
\hline hers & $-5.5^{\circ}$ & $-5.6^{\circ}$ & sofi & $26.2^{\circ}$ & $26.1^{\circ}$ \\
\hline joze & $3.4^{\circ}$ & $3.4^{\circ}$ & spt0 & $-4.8^{\circ}$ & $-4.0^{\circ}$ \\
\hline kiru & $-30.2^{\circ}$ & $-28.9^{\circ}$ & sulp & $24.6^{\circ}$ & $24.6^{\circ}$ \\
\hline lama & $12.8^{\circ}$ & $12.7^{\circ}$ & tlse & $-4.7^{\circ}$ & $-4.8^{\circ}$ \\
\hline leij & $9.2^{\circ}$ & $9.1^{\circ}$ & trol & $-0.8^{\circ}$ & $-0.2^{\circ}$ \\
\hline lroc & $-3.6^{\circ}$ & $-3.7^{\circ}$ & uzhl & $15.6^{\circ}$ & $15.6^{\circ}$ \\
\hline madr & $-15.9^{\circ}$ & $-16.1^{\circ}$ & vill & $1.9^{\circ}$ & $1.6^{\circ}$ \\
\hline mate & $5.1^{\circ}$ & $5.1^{\circ}$ & wroc & $16.8^{\circ}$ & $16.8^{\circ}$ \\
\hline medi & $4.3^{\circ}$ & $4.1^{\circ}$ & wsrt & $3.9^{\circ}$ & $3.9^{\circ}$ \\
\hline mets & $8.4^{\circ}$ & $9.1^{\circ}$ & wtzr & $13.0^{\circ}$ & $13.0^{\circ}$ \\
\hline mikl & $32.9^{\circ}$ & $32.9^{\circ}$ & yebe & $-12.4^{\circ}$ & $-12.5^{\circ}$ \\
\hline morp & $-19.1^{\circ}$ & $-19.0^{\circ}$ & zimm & $7.5^{\circ}$ & $7.6^{\circ}$ \\
\hline not1 & $-24.3^{\circ}$ & $-24.5^{\circ}$ & & & \\
\hline
\end{tabular}

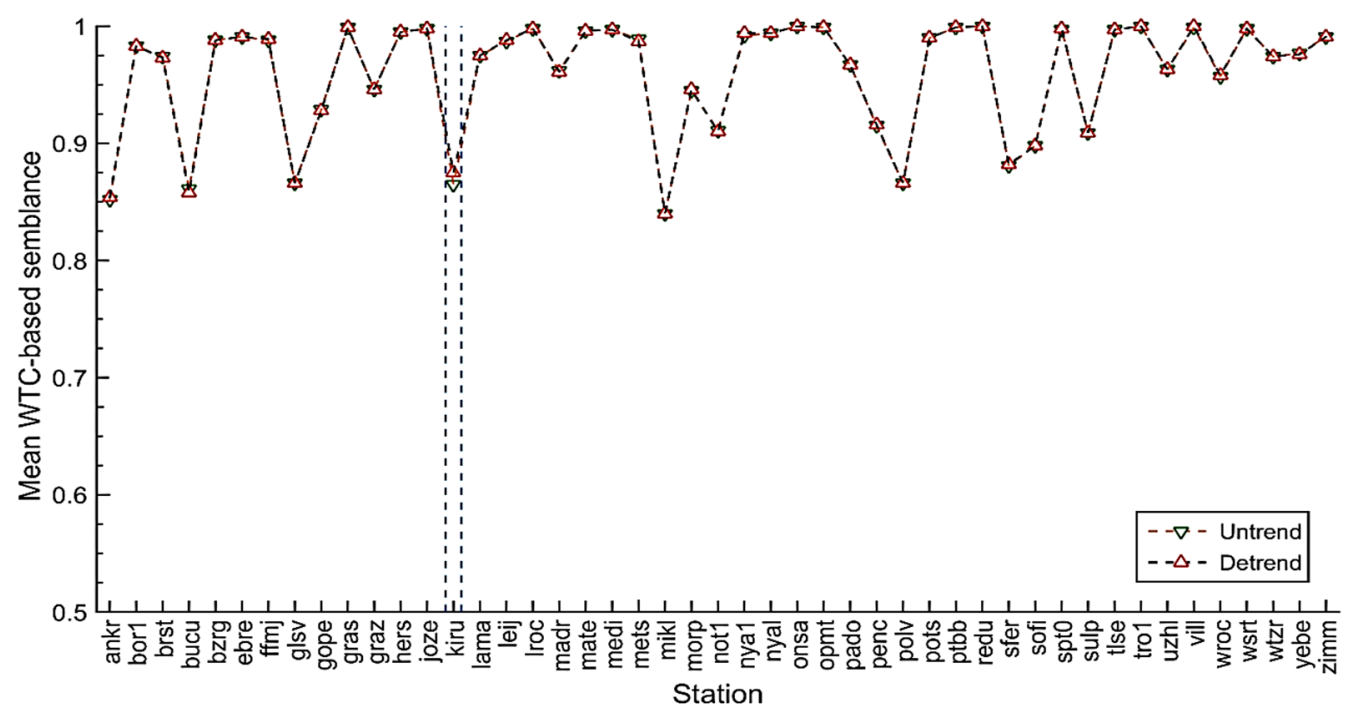

Fig. 9 The average values of the WTC-based semblance that is outside the COI at the period closest to 1 yr for the 47 stations.

relatively small. This shows that the spatial correlation between the GPS height and GRACE hydrological load vertical deformation is consistent with the percentage reduction of the GPS spatial RMS. In addition, the RMS value of the GPS high time series is reduced after the GRACE hydrological load deformation correction, with an average reduction value of $24.60 \%$, which indicates the feasibility of using the GRACE hydrological load to correct the GPS height time series. At the same time, we can also see that the RMS has a relatively small reduction for the ANKR and KIRU stations, with a reduction of less than $16 \%$, and the relative phase between the GPS height and the GRACE hydrological load deformation is obviously asynchronous. 


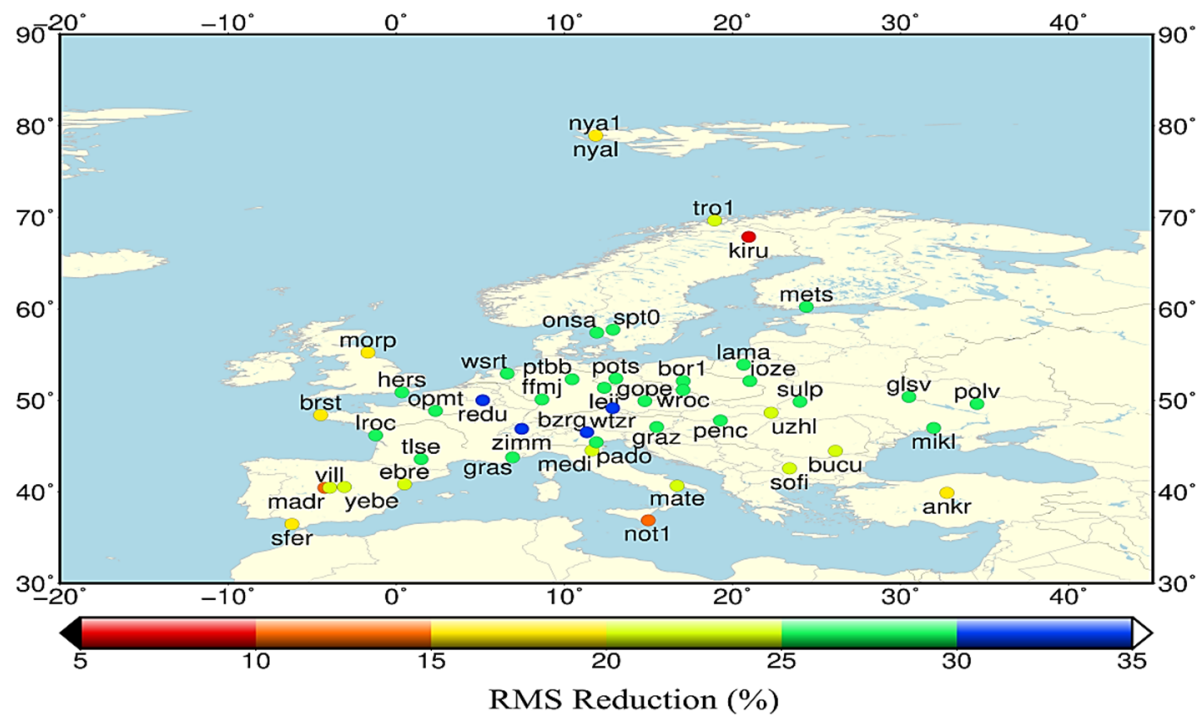

Fig. 10 GPS RMS reduction (\%) obtained by subtracting GRACE hydrological vertical deformation from GPS height for 47 GPS stations.

\section{DISCUSSION}

\subsection{DIFFERENCES OF HYDROLOGICAL LOAD DEFORMATION BETWEEN GRACE AND GLDAS}

Davis et al. (2004) and Morira et al. (2016) found that GRACE had better hydrological load effect than GLDAS, derived by studying the correction analysis of the hydrological load on the GPS observation time series in the Amazon region, which may be related to the land water and groundwater signals, as further discussed in Ferreira et al. (2019). For Europe, the overall elevation is low, the snow exists in high mountains, and the water network is dense on the mainland, making the hydrological vertical load effect obvious. However, compared with GRACE, GLDAS data only includes soil water, snow, and canopy water, but not surface water (rivers, lakes) and groundwater, so the hydrological load effect is weaker that than of GRACE. In addition, the main issue is the spectral inconsistencies as has been discussed in Ferreira et al. (2020).

\subsection{COMPARISON BETWEEN GPS HEIGHT TIME SERIES AND GRACE LOAD DEFORMATION}

Generally, the GPS and GRACE data sets are highly consistent in the amplitude and phase of annual vertical signals at most stations. In this study, the GPS and GRACE data have differences in the amplitude and phase of the vertical deformation. Tregoning et al. (2010) thought that the differences between them were mainly caused by the local effect of the station and the inadequate spatial resolution of GRACE. Based on the RMS of GPS stations, the RMS is partially reduced by the modification of the GRACE surface water load. Therefore, the hydrological load deformation derived by GRACE is smaller than the height of GPS (Ma, 2017). Another reason is that the GRACE hydrological load vertical deformation and regional
GPS height have certain errors in estimation. For example, in terms of GPS coordinate data, the fluctuation errors of the model mainly come from the orbit model error, different environmental load effects (atmosphere, non-tidal ocean, and hydrological load), temperature, and the Earth's rotation, amongst other factors. However, for the GRACE time-varying gravity field model to calculate the vertical deformation of the load, the main errors are the idealization of the crust hypothesis, the omission error, the correlation error of the spherical harmonic coefficient, and the signal leakage in the inversion process. In addition, other geophysical effects (e.g., groundwater) and errors in hydrological load deformation modeling (e.g., interpolation algorithm) may also lead to the phase asynchrony between the GPS observation and the GRACE hydrological load.

\subsection{REGIONAL DIFFERENCES OF THE GPS HYDROLOGICAL LOAD CORRECTION}

In the analysis of the correlation between the GPS height and GRACE hydrological load vertical deformation and the reduction percentage of the GPS high RMS, there are obvious spatial and regional characteristics, which are caused by various complex natural factors. For example, the main reason for the obvious hydrological load effect of the ZIMM station is that the station is located in the Alps Mountains, which include such peaks as Mont Blanc and Monte Rosa. It is precisely because the snow on these peaks does not melt all the year round that the hydrological load of the ZIMM station is relatively large. However, the internal regional stations of the European continent (e.g., GLSV and POLV) are relatively low in elevation, distributed along the Dnieper River, close to the inland river water source, and have relatively high soil moisture, which results in a relatively large 
hydrological load of the stations. In addition, the hydrological load is also related to the climate around the station (e.g., temperature, precipitation, and evaporation) and the vegetation coverage, so its causes are relatively complex and there is a need to consider a variety of factors.

\section{CONCLUSIONS}

Based on the study of the vertical deformation of the hydrological load at IGS stations over Europe, GRACE is used to monitor the influence of the hydrological load on the non-linear motion of GPS stations. The main conclusions are as follows:

1. By comparing the vertical deformation of the GRACE and GLDAS hydrological loads with GPS stations, we find that GRACE is closer to the GPS in seasonal signal amplitude; For correlation, the number of stations between GPS and GRACE with correlation coefficients over $0.7(79 \%)$ is larger than that between GPS and GLDAS (66\%); For RMS, the amplitude and scatter of the GRACE hydrological load seasonal fluctuation signal is better than that of GLDAS. In a word, the monitoring of the hydrological load effect based on GRACE is better than that of GLDAS, which has not been studied before in Europe.

2. On the vertical deformation annual period and relative phase signals of GPS and GRACE data, we find that the ZIMM station annual periodic signals, extracted by SSA, show good agreement, while the KIRU station show a significant difference. Through the average phase semblances calculate by WTC, it is found that the average value of the WTC-based semblance for most stations ranges from 0.96 to 1.0 , and that some stations (e.g., ANKR, KIRU, and MIKL) do not exceed 0.86. It indicates that the GRACE hydrological load deformation is not the complete expression of the driving force for the GPS stations non-linear motion. In addition, the relative phase of the WTC solution is basically consistent under non-detrend and detrend, and is generally relatively stable, indicating that the long-term tectonic deformation of the crust has little effect on the relative phase angle calculated by WTC, which can help us better understand the causes of phase differences in seasonal changes in the future.

3. In terms of correlation and RMS reduction, the correlation coefficients of $85 \%$ of the stations exceed 0.7, which indicates that there is a significant hydrological load effect in Europe. At the same time, in the inland area and around the high mountains, we found that the correlation coefficients of the stations are obviously greater than 0.8 , and the average RMS reduction value is $24.60 \%$ (e.g., ZIMM and LAMA), while the correlation coefficients of the stations in the Mediterranean and the coastal ocean are relatively small, even less than 0.6 , and the RMS reduction percentage is less than $16 \%$ (e.g., ANKR and
KIRU). This indicates that the hydrological load effect of the GPS stations over Europe has obvious spatial and regional characteristics, which help us better understand the GPS observations from the view of the hydrological load. Finally, the reasons for the differences of the hydrological load deformation among GPS, GRACE and GLDAS, and the reasons for the spatial characteristics of the GPS height modified by GRACE are discussed.

\section{ACKNOWLEDGMENT}

We are very grateful to Center for Space Research (CSR) for providing RL06 data. We thank GGFC for making the gridded hydrological loading from GLDAS mass distributions, and the Scripps Orbit and Permanent Array Center for providing GPS data. This work was supported in part by the National Key R\&D Program of China (2018YFC1508603).

\section{REFERENCES}

Bian, Y.K., Yue, J.P., Gao, W., Li, Z., Lu, D.K., Xiang, Y.F. and Chen, J.: 2019, Analysis of the spatiotemporal changes of ice sheet mass and driving factors in Greenland. Remote Sens., 11, 7, 862. DOI: $10.3390 / \mathrm{rs} 11070862$

Bos, M.S., Williams, S.D.P., Araújo, I.B. and Bastos, L.: 2014, The effect of temporal correlated noise on the sea level rate and acceleration uncertainty. Geophys. J. Int., 196, 3, 1423-1430. DOI: 10.1093/gji/ggt481

Cazenave, A. and Chen, J.: 2010, Time-variable gravity from space and present-day mass redistribution in the Earth system. Earth Planet. Sci. Lett., 298, 3-4, 263 274. DOI: 10.1016/j.eps1.2010.07.035

Chen, J.L., Rodell, M., Wilson, C.R. and Famiglietti, J.S.: 2005, Low degree spherical harmonic influences on Gravity Recovery and Climate Experiment (GRACE) water storage estimates. Geophys. Res. Lett., 32, 14, L14405. DOI: 10.1029/2005GL022964

Chen, J.L., Wilson, C.R., Blankenship, D. and Tapley, B.D.: 2009, Accelerated Antarctic ice loss from satellite gravity measurements. Nat. Geosci., 2, 12, 859-862. DOI: 10.1038/NGEO694

Chen, J.L., Wilson, C.R. and Tapley, B.D.: 2011, Interannual variability of Greenland ice losses from satellite gravimetry. J. Geophys. Res., Solid Earth., 116, B7, B07406. DOI: 10.1029/2010JB007789

Cooper, G.R.J. and Cowan, D.R.: 2008, Comparing time series using wavelet-based semblance analysis. Comput. Geosci., 34, 2, 95-102. DOI: $10.1016 /$ j.cageo.2007.03.009

Davis, J.L.: 2004, Climate-driven deformation of the solid Earth from GRACE and GPS. Geophys. Res. Lett., 31, 24, L24605. DOI: 10.1029/2004GL021435

Deng, L.S.: 2016, Research on effects of unmodeled errors and environmental loading on GPS coordinate time series. PhD thesis, Wuhan University, China.

Dill, R. and Dobslaw, H.: 2013, Numerical simulations of global-scale high-resolution hydrological crustal deformations. J. Geophys. Res. Solid Earth., 118, 9, 5008-5017. DOI: 10.1002/jgrb.50353

Dill, R., Klemann, V., Martinec, Z. and Tesauro, M.: 2015, Applying local Green's functions to study the influence of the crustal structure on hydrological loading displacements. J. Geodyn., 88, 14-22. DOI: 10.1016/j.jog.2015.04.005 
Dixon, T.H.: 1991, An introduction to the global positioning system and some geological applications. Rev. Geophys., 29, 2, 249-276. DOI: 10.1029/91RG00152

Ding, Y.H., Huang, D.F., Shi, Y.L., Jiang, Z.S. and Chen, T.: 2018, Determination of vertical surface displacements in Sichuan using GPS and GRACE measurements. Chin. J. Geophys., 61, 12, 4777-4778. DOI: $10.1073 /$ pnas.1413325111

Dow, J.M., Neilan, R. and Rizos, C.: 2009, The International GNSS service in a changing landscape of global navigation satellite systems. J. Geod., 83, 3-4, 191198. DOI: $10.1007 / \mathrm{s} 00190-008-0300-3$

Farrell, W.E.: 1972, Deformation of the Earth by surface loads. Rev. Geophys., 10, 3, 761-797.

Ferreira, V.G., Montecino, H.C., Ndehedehe, C.E., Heck, B., Gong, Z., de Freitas, S.R.C. and Westerhaus, M.: 2018, Space-based observations of crustal deflections for drought characterization in Brazil. Sci. Total Environ., 644, 256-273.

DOI: $10.1016 /$ j.scitotenv.2018.06.277

Ferreira, V.G., Montecino, H.D., Ndehedehe, C.E., del Rio, R.A., Cuevas, A. and de Freitas, S.R.C.: 2019, Determining seasonal displacements of Earth's crust in South America using observations from spaceborne geodetic sensors and surface-loading models. Earth Planets Space, 71, 84.

DOI: 10.1016/s40623-019-1062-2

Ferreira, V.G., Liu, Z., Montecino, H.C., Yuan, P., Kelly, C.I., Mohammed, A.S., Han, L.Y.: 2020, Reciprocal comparison of geodetically sensed and modeled vertical hydrological loading products. Acta Geod. Geophys., 55, 1, 23-49. DOI: $10.1007 / \mathrm{s} 40328-019-00279-\mathrm{z}$

Fritsche, M., Döll, P. and Dietrich, R.: 2012, Global-scale validation of model-based load deformation of the Earth's crust from continental watermass and atmospheric pressure variations using GPS. J. Geodyn., 59, 60, 133-142.

DOI: $10.1016 /$ j.jog.2011.04.001

Fu, Y. and Freymueller, J.T.: 2012a, Seasonal and long-term vertical deformation in the Nepal Himalaya constrained by GPS and GRACE measurements. J. Geophys. Res., Solid Earth., 117, B3, B03407. DOI: $10.1029 / 2011$ JB008925

Fu, Y., Freymueller, J.T. and Jensen, T.: 2012b, Seasonal hydrological loading in southern Alaska observed by GPS and GRACE. Geophys. Res. Lett., 39, 15, L1531. DOI: 10.1029/2012GL052453

Geng, J., Williams, S.D.P., Teferle, F.N. and Dodson, A.H.: 2012, Detecting storm surge loading deformations around the southern North Sea using subdaily GPS. Geophys. J. Int., 191, 2, 569-578. DOI: $10.1111 /$ j.1365-246X.2012.05656.x

Geruo, A., Wahr, J. and Zhong, S.: 2013, Computations of the viscoelastic response of a 3-D compressible Earth to surface loading: An application to Glacial Isostatic Adjustment in Antarctica and Canada. Geophys. J. Int., 192, 2, 557-572. DOI: 10.1093/gji/ggs030

Ghil, M., Allen, M.R., Dettinger, M.D., Ide, K., Kondrashov, D., Mann, M.E., Robertson, A.W., Saunders, A., Tian, Y., Varadi, F. and Yiou, P.: 2002, Advanced spectral methods for climatic time series. Rev. Geophys., 40, 1, 3-1-41. DOI: 10.1029/2000RG000092

Göttl, F., Schmidt, M. and Seitz, F.: 2018, Mass-related excitation of polar motion: An assessment of the new RL06 GRACE gravity field models. Earth Planets Space, 70, 1, 195. DOI: 10.1186/s40623-018-0968-4
Grinsted, A., Moore, J.C. and Jevrejeva, S.: 2004, Application of the cross wavelet transform and wavelet coherence to geophysical time series. Nonlinear Proc. Geoph., 11, 5-6, 561-566. DOI: $10.5194 /$ npg-11-561-2004

Hao, M., Freymueller, J.T., Wang, Q., Cui, D. and Qin, S.: 2016, Vertical crustal movement around the southeastern Tibetan Plateau constrained by GPS and GRACE data. Earth Planet. Sci. Lett., 437, 1-8. DOI: $10.1016 /$ j.epsl.2015.12.038

Han, S.-C., Shum, C.K., Jekeli, C., Kuo, C.-Y., Wilson, C. and Seo, K.-W.: 2005, Non-isotropic filtering of GRACE temporal gravity for geophysical signal enhancement. Geophys. J. Int., 163, 1, 18-25. DOI: $10.1111 / \mathrm{j} .1365-246 X .2005 .02756 . \mathrm{x}$

Han, S.-C.: 2017, Elastic deformation of the Australian continent induced by seasonal water cycles and the 2010-2011 La Niña determined using GPS and GRACE. Geophys. Res. Lett., 44, 6, 2763-2772. DOI: 10.1002/2017GL072999

Jiang, W.P., Li, Z., Liu, W.K. and Zhou, X.H.: 2010, Some thoughts on establishment and maintenance of terrestrial reference frame considering non-linear variation. Geomatics and Information Science of Wuhan University, 35, 6, 665-669.

Jiang, W.P., Li, Z., Liu, H.F. and Zhao, Q.: 2013, Cause analysis of the non-linear variation of the IGS reference station coordinate time series in China. Chin. J. Geophys., 56, 7, 2228-2237. DOI: $10.1002 /$ cjg.2.20033

Jiang, W.P., Xia, C.Y., Li, Z., Guo, Q.Y. and Zhang, S.Q.: 2014, Analysis of environmental loading effects on regional GPS coordinate time series. Acta Geod. et Cartogr. Sin., 43, 12, 1217-1223, (in Chinese with English abstract).

King, M., Moore, P., Clarke, P. and Lavallée, D.: 2006, Choice of optimal averaging radii for temporal GRACE gravity solutions, a comparison with GPS and satellite altimetry. Geophys. J. Int., 166, 1, 1-11. DOI: 10.1111/j.1365-246X.2006.03017.x

Klos, A., Bos, M.S. and Bogusz, J.: 2018, Detecting timevarying seasonal signal in GPS position time series with different noise levels. GPS Solut., 22, 21. DOI: 10.1007/s10291-017-0686-6

Knappe, E., Bendick, R., Martens, H.R., Argus, D.F. and Gardner, W.P.: 2019, Downscaling vertical GPS observations to derive Watershed-Scale Hydrologic Loading in the Northern Rockies. Water Resour. Res., 55, 1, 391-401. DOI: 10.1029/2018WR023289

Kusche, J.: 2007, Approximate decorrelation and nonisotropic smoothing of time-variable GRACE-type gravity field models. J. Geod., 81, 11, 733-749. DOI: $10.1007 / \mathrm{s} 00190-007-0143-3$

Langbein, J.: 2004, Noise in two-color electronic distance meter measurements revisited. J. Geophys. Res., Solid Earth., 109, B04406. DOI: 10.1029/2003JB002819

Lavallée, D. and Blewitt, G.: 2002, Degree-1 Earth deformation from very long baseline interferometry. Geophys. Res. Lett., 29, 20, 281-284. DOI: $10.1029 / 2002$ GL015883

Liu, L., Khan, S.A., van Dam, T. and Ma, J.H.Y.: 2017, Annual variations in GPS-measured vertical displacements near Upernavik Isstrøm (Greenland) and contributions from surface mass loading: Annual GPS Verticals in Greenland. J. Geophys. Res., Solid Earth., 122, 1, 677-691. DOI: 10.1002/2016JB013494 
Li, S.Y., Shen, W.B., Pan, Y.J., Zhang, T.X.: 2020, Surface seasonal mass changes and vertical crustal deformation in North China from GPS and GRACE measurements. Geod. Geodyn., 11, 1, 46-55. DOI: 10.1016/j.geog.2019.05.002

Li, Z., Yue, J.P., Li, W., Lu, D.K. and Li, X.G.: 2017a, A comparison of hydrological deformation using GPS and global hydrological model for the Eurasian Plate. Adv. Space Res., $60,3,587-596$. DOI: $10.1016 /$ j.asr.2017.04.023

Li, Z., Yue, J.P., Li, W. and Lu, D.K.: 2017b, Investigating mass loading contributes of annual GPS observations for the Eurasian plate. J. Geodyn., 111, 43-49. DOI: 10.1016/j.jog.2017.07.001

Li, Z., Yue, J.P., Hu, J.Y., Xiang, Y.F., Chen, J. and Bian, Y.K.: 2018, Effect of surface mass loading on geodetic GPS observations. Appl. Sci., 8, 10, 1851. DOI: $10.3390 / \mathrm{app} 8101851$

Ma, F.X.: 2017, The research of the influence of environmental loading on non-linear motion of European GPS stations. PhD thesis, Wuhan University, China.

Moreira, D.M., Calmant, S., Perosanz, F., Xavier, L., Filho, O.C.R., Seyler, F. and Monteiro, A.C.: 2016, Comparisons of observed and modeled elastic responses to hydrological loading in the Amazon Basin. Geophys. Res. Lett., 43, 18, 9604-9610. DOI: 10.1002/2016GL070265

Nahmani, S., Bock, O., Bouin, M.-N., SantamaríaGómez, A., Boy, J.-P., Collilieux, X., Métivier, L., Panet, I., Genthon, P., de Linage, C. and Wöppelmann, G.: 2012, Hydrological deformation induced by the West African Monsoon: Comparison of GPS, GRACE and loading models. J. Geophys. Res., Solid Earth, 117, B5, B05409. DOI: 10.1029/2011JB009102

Nikolaidis, R.: 2002, Observation of geodetic and seismic deformation with the global positioning system. PhD thesis, University of California, San Diego.

Ray, J., Griffiths, J., Collilieux, X. and Rebischung, P.: 2013, Subseasonal GNSS positioning errors. Geophys. Res. Lett., 40, 22, 5854-5860. DOI: $10.1002 / 2013$ GL058160

Rajner, M. and Liwosz, T.: 2011, Studies of crustal deformation due to hydrological loading on GPS height estimates. Geod. Cartogr., 60, 2, 135144. DOI: 10.2478/v10277-012-0012-y

Rodriguez-Solano, C.J., Hugentobler, U., Steigenberger, P., Blosfeld, M. and Fritsche, M.: 2014, Reducing the draconitic errors in GNSS geodetic products. J. Geod., 88, 6, 559-574. DOI: $10.1007 / \mathrm{s} 00190-014-0704-1$

Rodell, M., Houser, P.R., Jambor, U., Gottschalck, J., Mitchell, K., Meng, C.-J., Arsenault, K., Cosgrove, B., Radakovich, J., Bosilovich, M., Entin, J.K., Walker, J.P. and Toll, D.: 2004., The global land data assimilation system. Bull. Am. Soc., 85, 3, 381-394. DOI: $10.1175 /$ BAMS-85-3-381

Rui, H.: 2011, Readme document for global land data assimilation. Version 1(GLDAS-1). Products at http://disc. sci. gsfc. nasa gov/services/gradsgds/gldas.
Swenson, S. and Wahr, J.: 2006, Post-processing removal of correlated errors in GRACE data. Geophys. Res. Lett., 33, 8, L08402. DOI: 10.1029/2005GL025285

Swenson, S. Chambers, D. and Wahr, J.: 2008, Estimating geocenter variations from a combination of GRACE and ocean model output. J. Geophys. Res., Solid Earth., 113, B8, B08410.

DOI: $10.1029 / 2007$ JB005338

Tesmer, V., Steigenberger, P., van Dam, T. and Mayer-Gürr, T.: 2011, Vertical deformations from homogeneously processed GRACE and global GPS long-term series. J. Geod., 85, 5, 291-310. DOI: $10.1007 / \mathrm{s} 00190-010-0437-8$

Torrence, C., and Compo, G.P.: 1998, A practical guide to wavelet analysis. Bull. Am. Meteorol. Soc., 79, 1, 6178. DOI: $10.1175 / 1520-0477(1998) 079$

Tregoning, P., Watson, C., Ramillien, G., McQueen, H. and Zhang, J.: 2009, Detecting hydrologic deformation using GRACE and GPS. Geophys. Res. Lett., 36, 15, 139-156. DOI: 10.1029/2009GL038718

van Dam, T., Wahr, J., Milly, P.C.D., Shmakin, A.B., Blewitt, G., Lavallée, D. and Larson, K.M.: 2001, Crustal displacements due to continental water loading. Geophys. Res. Lett., 28, 4, 651-654. DOI: 10.1029/2000GL012120

van Dam, T., Wahr, J. and Lavallée, D.A.: 2007, Comparison of annual vertical crustal displacements from GPS and Gravity Recovery and Climate Experiment (GRACE) over Europe. J. Geophys. Res., Solid Earth., 112, B3, B03404. DOI: $10.1029 / 2006 J B 004335$

van Dam, T., Collilieux, X., Rebischung, P., Ray, J. and Altamimi, Z.: 2011, Quantifying load model errors by comparison to a global GPS time series solution. AGU Fall Meeting Abstracts, G53B-0905.

Vautard, R., Yiou, P. and Ghil, M.: 1992. Singular-spectrum analysis: A toolkit forshort, noisy chaotic signals. Physica D., 58, 1-4, 95-126. DOI: 10.1016/0167-2789(92)90103-T

Velicogna, I., Wahr, J. and Vanden Dool, H.: 2001, Can surface pressure be used to remove atmospheric contributions from GRACE data with sufficient accuracy to recover hydrological signals? J. Geophys. Res., Solid Earth., 106, B8, 16415-16434. DOI: 10.1029/2001JB000228

Wahr, J., Molenaar, M. and Bryan, F.: 1998, Time variability of the Earth's gravity field: Hydrological and oceanic effects and their possible detection using GRACE. J. Geophys. Res., Solid Earth., 103, B12, 30205-30229. DOI: 10.1029/98JB02844

Wu, Y. L., Zhao, Q., Zhang, B. and Wu, W.W.: 2017, Characterizing the seasonal crustal motion in Tianshan Area using GPS, GRACE and Surface Loading Models. Remote Sens., 9, 12, 1303. DOI: $10.3390 / \mathrm{rs} 9121303$

Xiang, Y.F., Yue, J.P., Cong, K.L., Xing, Y. and Cai, D.J.: 2019 , Characterizing the seasonal hydrological loading over the Asian continent using GPS, GRACE, and hydrological model. Pure Appl. Geophys., 176, 11, 5051-5068. DOI: 10.1007/s00024-019-02251-y

Xu, C.: 2017a, Evaluating mass loading products by comparison to GPS array daily solutions. Geophys. J. Int., 208, 1, 24-35. DOI: 10.1093/gji/ggw385

Xu, C.: 2017b, Detecting periodic oscillations in astronomy data: revisiting wavelet analysis with coloured and white noise. Mon. Not. R. Astron. Soc., 466, 4, $3827-$ 3833. DOI: $10.1093 / \mathrm{mnras} / \mathrm{stw} .3349$ 